\title{
Article
}

\section{Towards P-Type Conduction in Hexagonal Boron Nitride: Doping Study and Electrical Measurements Analysis of hBN/AlGaN Heterojunctions}

\author{
Adama Mballo 1(D), Ashutosh Srivastava ${ }^{1,2}$, Suresh Sundaram ${ }^{1,3}{ }^{(\mathbb{D})}$, Phuong Vuong ${ }^{1}$, Soufiane Karrakchou ${ }^{1,2}$, \\ Yacine Halfaya ${ }^{4} \oplus^{\circ}$, Simon Gautier ${ }^{4}$, Paul L. Voss ${ }^{1,2}$, Ali Ahaitouf ${ }^{1,3,+}+^{(}$, Jean Paul Salvestrini ${ }^{1,2,3}$ \\ and Abdallah Ougazzaden 1,2,*
}

check for

updates

Citation: Mballo, A.; Srivastava, A.; Sundaram, S.; Vuong, P.; Karrakchou, S.; Halfaya, Y.; Gautier, S.; Voss, P.L.; Ahaitouf, A.; Salvestrini, J.P.; et al. Towards P-Type Conduction in Hexagonal Boron Nitride: Doping Study and Electrical Measurements Analysis of hBN/AlGaN

Heterojunctions. Nanomaterials 2021, 11, 211. https://doi.org/10.3390/ nano11010211

Received: 14 December 2020 Accepted: 13 January 2021 Published: 15 January 2021

Publisher's Note: MDPI stays neutral with regard to jurisdictional clai$\mathrm{ms}$ in published maps and institutional affiliations.

Copyright: (C) 2021 by the authors. Licensee MDPI, Basel, Switzerland. This article is an open access article distributed under the terms and conditions of the Creative Commons Attribution (CC BY) license (https:// creativecommons.org/licenses/by/ $4.0 /)$.
1 CNRS, UMI 2958, GT-CNRS, 2 rue Marconi, 57070 Metz, France; amballo@georgiatech-metz.fr (A.M.); asrvast@georgiatech-metz.fr (A.S.); ssundara@georgiatech-metz.fr (S.S.); pvuong@georgiatech-metz.fr (P.V.); soufiane.karrakchou@gatech.edu (S.K.); paul.voss@ece.gatech.edu (P.L.V.); ali.ahaitouf@georgiatech-metz.fr or ali.ahaitouf@usmba.ac.ma (A.A.); jean-paul.salvestrini@georgiatech-metz.fr (J.P.S.)

2 School of Electrical and Computer Engineering, Georgia Institute of Technology, GT-Lorraine, 57070 Metz, France

3 Georgia Tech-Lorraine, 2 rue Marconi, 57070 Metz, France

4 Institut Lafayette, 2 rue Marconi, 57070 Metz, France; yacine.halfaya@institutlafayette.eu (Y.H.); simon.gautier@institutlafayette.eu (S.G.)

* Correspondence: abdallah.ougazzaden@georgiatech-metz.fr

+ Permanent Address: SIGER Laboratory, Faculty of Sciences and Technology, Sidi Mohammed ben Abdellah University, P.O. Box 2202 Fes, Morocco.

\begin{abstract}
Reliable p-doped hexagonal boron nitride (h-BN) could enable wide bandgap optoelectronic devices such as deep ultra-violet light emitting diodes (UV LEDs), solar blind photodiodes and neutron detectors. We report the study of $\mathrm{Mg}$ in h-BN layers as well as $\mathrm{Mg}$ h-BN/AlGaN heterostructures. $\mathrm{Mg}$ incorporation in $\mathrm{h}-\mathrm{BN}$ was studied under different biscyclopentadienyl-magnesium

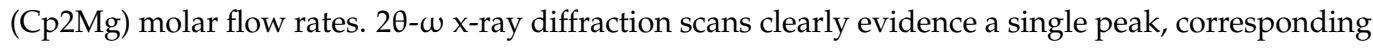
to the (002) reflection plane of h-BN with a full-width half maximum increasing with $\mathrm{Mg}$ incorporation in $\mathrm{h}-\mathrm{BN}$. For a large range of $\mathrm{Cp} 2 \mathrm{Mg}$ molar flow rates, the surface of $\mathrm{Mg}$ doped $\mathrm{h}$-BN layers exhibited characteristic pleats, confirming that $\mathrm{Mg}$ doped $\mathrm{h}-\mathrm{BN}$ remains layered. Secondary ion mass spectrometry analysis showed $\mathrm{Mg}$ incorporation, up to $4 \times 10^{18} / \mathrm{cm}^{3}$ in h-BN. Electrical conductivity of $\mathrm{Mg}$ h-BN increased with increased $\mathrm{Mg}$-doping. Heterostructures of $\mathrm{Mg}$ h-BN grown on $\mathrm{n}$-type $\mathrm{Al}$ rich $\mathrm{AlGaN}$ (58\% Al content) were made with the intent of forming a p-n heterojunction. The I-V characteristics revealed rectifying behavior for temperatures from 123 to $423 \mathrm{~K}$. Under ultraviolet illumination, photocurrent was generated, as is typical for $\mathrm{p}-\mathrm{n}$ diodes. $\mathrm{C}-\mathrm{V}$ measurements evidence a built-in potential of $3.89 \mathrm{~V}$. These encouraging results can indicate p-type behavior, opening a pathway for a new class of wide bandgap p-type layers.
\end{abstract}

Keywords: h-BN; magnesium; doping; wide bandgap; heterojunction

\section{Introduction}

Control of doping and conductivity is of critical importance for fabrication of semiconductor-based devices. For example, in III-nitride-based deep ultraviolet (DUV) LEDs, the p-type doping of $\mathrm{Al}$ rich $\mathrm{AlGaN}$ with $\mathrm{Mg}$ is extremely challenging because of its large ionization energy in $\mathrm{AlN}(\sim 500 \mathrm{meV})$ [1-5]. An alternate wide bandgap material with appropriate p-type doping is highly desired. Hexagonal boron nitride (h-BN) is a promising material for p-type wide bandgap nitride such as UV-LEDs [6-9] and UV detectors [10-12].

Previously, it was reported that the p doping of h-BN can be achieved using $\mathrm{Zn}, \mathrm{Be}$ and $\mathrm{Mg}$ as dopants [13-20]. More recently, contradicting experimental and theoretical 
studies of p-type conductivity of h-BN have been published. Experimental works report good control of p-type conductivity of h-BN by means of in situ doping of magnesium, with activation energy of $30-300 \mathrm{meV}[7,18,19]$. On the other hand, density functional theory (DFT) studies predict that p-type h-BN using Mg is most likely impossible because of the formation of small hole polarons, which increases the Mg ionization energy to more than $1 \mathrm{eV}$ [21]. Other experimental studies point to defect states with energies near the valence band as a mechanism that can lead to effective doping [15]. In this paper, we report an experimental study of the electrical behavior of $\mathrm{Mg}$ incorporation in h-BN. In order to evaluate the potential of h-BN with $\mathrm{Mg}$ doping for device applications, we fabricate $\mathrm{Mg}$ doped $\mathrm{h}-\mathrm{BN} / \mathrm{n}-\mathrm{AlGaN}$ heterostructures and report I-V characteristics as a function of temperature, under $\mathrm{UV}$ illumination and $\mathrm{C}-\mathrm{V}$ measurements at room temperature.

\section{Materials and Methods}

Materials were grown in a MOVPE close-coupled showerhead $3 \times 2$ " system on (0001) sapphire substrates using triethylboron (TEB), trimethylgallium (TMGa), trimethylaluminum (TMAl) and ammonia $\left(\mathrm{NH}_{3}\right)$ as $\mathrm{B}, \mathrm{Ga}, \mathrm{Al}$ and $\mathrm{N}$ precursors, respectively. The h-BN layers were grown at $1280{ }^{\circ} \mathrm{C}$ in hydrogen ambient at 85 mbar. The growth of $\mathrm{h}-\mathrm{BN}$ layers was initiated with a TEB preflow; details of these growth conditions have been reported elsewhere [22]. Biscyclopentadienyl-magnesium (Cp2Mg) was used as the source of $\mathrm{Mg}$ dopants. First, we grew $50 \mathrm{~nm}$ thick undoped h-BN, referred to as sample A, for reference. Then, we studied the effect of $\mathrm{Mg}$ doping on the structural and morphological characteristics of three different sets of h-BN samples referred to as $B, C$ and $D$, grown at $C p 2 \mathrm{Mg}$ molar flow rates of $0.9,1.8$ and $2.9 \mu \mathrm{mol} / \mathrm{min}$, respectively. The h-BN layer thickness of the full set of samples was $50 \mathrm{~nm}$, and all the other parameters including TEB molar flow were kept constant. In addition to these layers, two heterostructures made of $50 \mathrm{~nm}$ undoped and $\mathrm{Mg}$ doped h-BN grown on $500 \mathrm{~nm}$ thick $\mathrm{n}-\mathrm{AlGaN}$ (58\% Al composition, Si doped at $1.03 \times 10^{17} \mathrm{~cm}^{-3}$ ) on an AlN/sapphire template were grown. The first was grown with undoped $\mathrm{BN}$ on $\mathrm{n}-\mathrm{AlGaN}$ to be an i-n junction (sample E), and the second was grown with doped BN with the purpose of forming a p-n heterojunction (sample F). The n-AlGaN layer with $58 \% \mathrm{Al}$ content was chosen because $\mathrm{n}$-doped $\mathrm{BN}$ is experimentally infeasible and because it is difficult to have high quality n-doped AlN. The Cp2Mg molar flow used for sample $\mathrm{F}$ was the same as the one used for sample D $(2.9 \mu \mathrm{mol} / \mathrm{min})$. For the fabrication of samples $\mathrm{E}$ and $\mathrm{F}$, a standard photolithography-based process was employed. First, mesa-etching isolation was achieved by inductively coupled plasma with $\mathrm{BCl}_{3} / \mathrm{Cl}_{2} / \mathrm{Ar}$ chemistry. $\mathrm{Ti} / \mathrm{Al} / \mathrm{Ni} / \mathrm{Au}$ and $\mathrm{Ni}$ stacks were used for the n-contact and the p-contact, respectively. Each metal layer was deposited by thermal evaporation. $\mathrm{N}$-contact annealing was carried out at $1050{ }^{\circ} \mathrm{C}$ for $6 \mathrm{~s}$ under $\mathrm{N}_{2}$, then the p-contact was annealed at $1020^{\circ} \mathrm{C}$ for 60 s under $\mathrm{N}_{2}$ atmosphere.

The morphological and structural properties were characterized by a scanning electron microscope (SEM) and high-resolution X-ray diffraction (HR-XRD), respectively. The HRXRD scans were performed by a Panalytical X'pert Pro MRD system with $\mathrm{Cu} K \alpha$ radiation in triple axis mode. The FWHM value was determined for all the samples by fitting the (002) peak of the h-BN.

Secondary ion mass spectrometry (SIMS) measurements were carried out by an external company (Probion Analysis). Calibration was first performed using h-BN layers with different and controlled Mg implantation. Using this calibration data, grown samples with in situ doping were then characterized.

I-V and capacitance measurements were performed using a Keithly 4200A SMU and a Keysight E4990A impedance meter, respectively. I-V measurements were performed to verify the ohmic behavior of the contacts on $h-B N$ samples $A-D$ and to record the $p-B N / n-$ $\mathrm{AlGaN}$ diode characteristics. Photocurrent generation measurements used a quadrupled Nd:YAG laser with a power of $10 \mathrm{~mW}$ at a wavelength of $266 \mathrm{~nm}$ as an optical source. Van der Pauw (VdP) and Hall Effect measurements were performed to determine the resistivity and doping of the grown samples. 


\section{Results and Discussions \\ 3.1. Morphology and Structural Characterizations of Undoped and $\mathrm{Mg}$ Doped $h$-BN Layers}

The surface morphology of the undoped h-BN (sample A) and the Mg-doped h-BN samples (samples B-D) with three different Cp2Mg molar flows are shown in Figure 1. All the samples were optically transparent with a smooth surface as shown in the insets of Figure 1. Under SEM, the undoped h-BN sample exhibited an organized semihexagonal wrinkled surface (Figure 1a), which is comparable to our previous studies. Refer to [22,23] for detailed characterization. Wrinkle formation is the result of the compressive stress during sample cooling. Similar wrinkles were observed on the B and C h-BN samples (Figure $1 b, c)$. These surface morphologies confirm that the h-BN in samples A-C is layered. On the other hand, the h-BN sample D presented in Figure 1d shows wrinkled surface morphology decorated with a high density of particles. This morphological change can be directly correlated to the heavy Mg doping. Previous studies have shown that insufficient $\mathrm{NH}_{3}$ flow or a parasitic reaction between the precursors may lead to grain formation, which is $\mathrm{BN}$ in the disordered phase (turbostratic/amorphous) [24-27]. At high $\mathrm{Cp} 2 \mathrm{Mg}$ flow, $\mathrm{Mg}$ may block nitrogen atoms, leading to a low number of active $\mathrm{N}$ atoms in the growth front, resulting in stacking fault-induced variations in strain, which then generate a higher density of misoriented $\mathrm{BN}$ grains in sample $\mathrm{D}$.

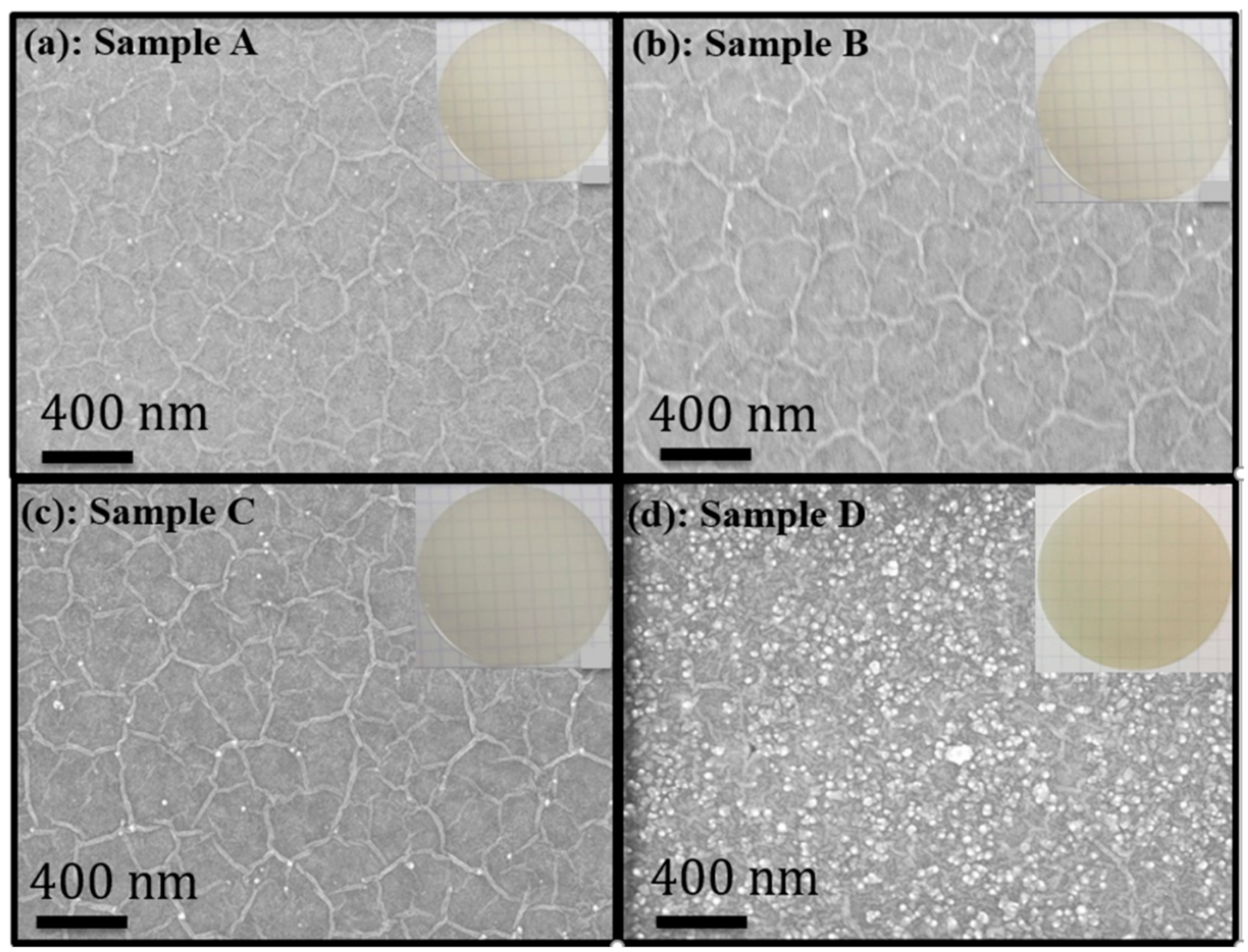

Figure 1. (a-d) SEM images of h-BN samples A, B, C and D, respectively. Insets show photographs of the respective samples. 
The crystalline characteristics of the as-grown samples were studied with HR-XRD $2 \theta-\omega$ scan measurements as shown in Figure 2. All the samples exhibited a peak around $26^{\circ}$ (Figure 2a) which is clearly the (002) plane reflection from the $\mathrm{sp}^{2}$-bonded h-BN. The (004) plane diffraction peak of $\mathrm{h}-\mathrm{BN}$ was also observed at $53.5^{\circ}$. However, the increase in $\mathrm{Mg}$ led to lower intensity and broader peaks. Furthermore, when compared to the peak position of sample A $\left(25.86^{\circ}\right)$, a shift of the (002) peak was observed in sample B $\left(25.72^{\circ}\right)$. This may be related to the deformation of the surrounding lattice because of the difference of atom sizes between B and Mg [20]. However, the peak shift at the lower angle was not observed in samples $C$ and $D$. This is related to the formation of an accumulation of disordered phases in samples $\mathrm{C}$ and $\mathrm{D}$, which overcomes the effect of $\mathrm{Mg}$ incorporation. It is assumed that all the $\mathrm{Mg}$ atoms are probably not in the substitutional sites of boron. Therefore, an increase in non-substitutional $\mathrm{Mg}$ incorporation with the increase in $\mathrm{Mg}$ flow may generate additional heterogeneous strain that contributes to the increase in the FWHM of (002) reflection (Figure 2b) [28]. This increase in FWHM suggests a degradation of the crystalline quality for samples B-D. Moreover, the asymmetric shape of the (002) peak in $\mathrm{D}$ is likely a result of localized variation of strain in $\mathrm{Mg}$ doped h-BN layers, which causes formation of a large number of disordered $\mathrm{BN}$ particles.
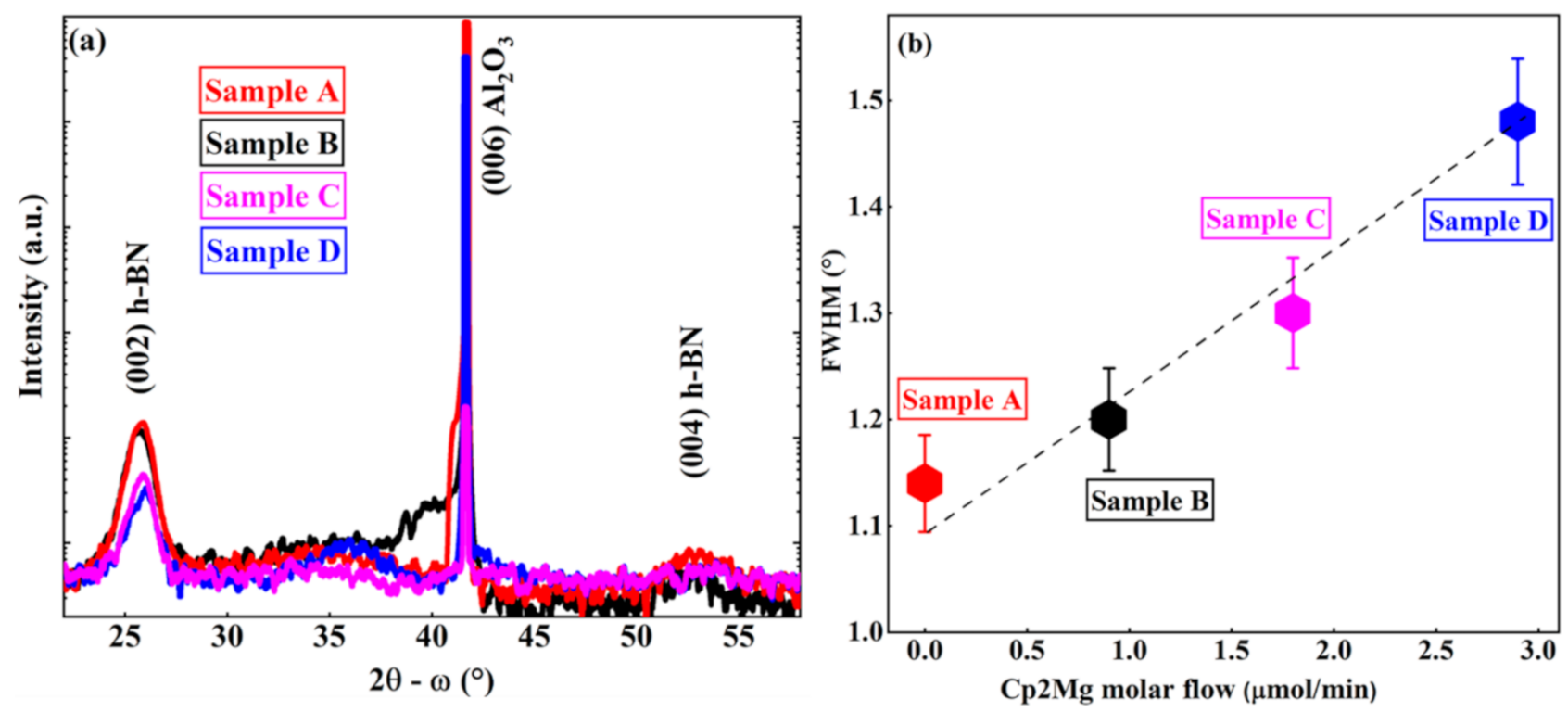

Figure 2. (a) HR-XRD 20- $\omega$ scans of the grown h-BN samples; (b) FWHM variation of (002) diffraction peak of the different h-BN samples versus Cp2Mg molar flow.

\subsection{SIMS Measurement of Mg Doping Concentration}

To estimate the $\mathrm{Mg}$ concentration in our h-BN films, secondary ion mass spectrometry (SIMS) measurements were performed. The Mg concentration increased super-linearly with the increase in Cp2Mg molar flows, as shown in Figure 3. Similar trends have been obtained in other III-V materials [29,30]. Mg incorporation reached $4 \times 10^{18}$ atoms $/ \mathrm{cm}^{3}$ for a Cp2Mg molar flow of $2.9 \mu \mathrm{mol} / \mathrm{min}$ (sample D). For the undoped sample, the value of $\mathrm{Mg}$ at $1 \times 10^{15}$ atoms $/ \mathrm{cm}^{3}$ corresponds to the limit of SIMS detection and does not correspond to a real concentration. 


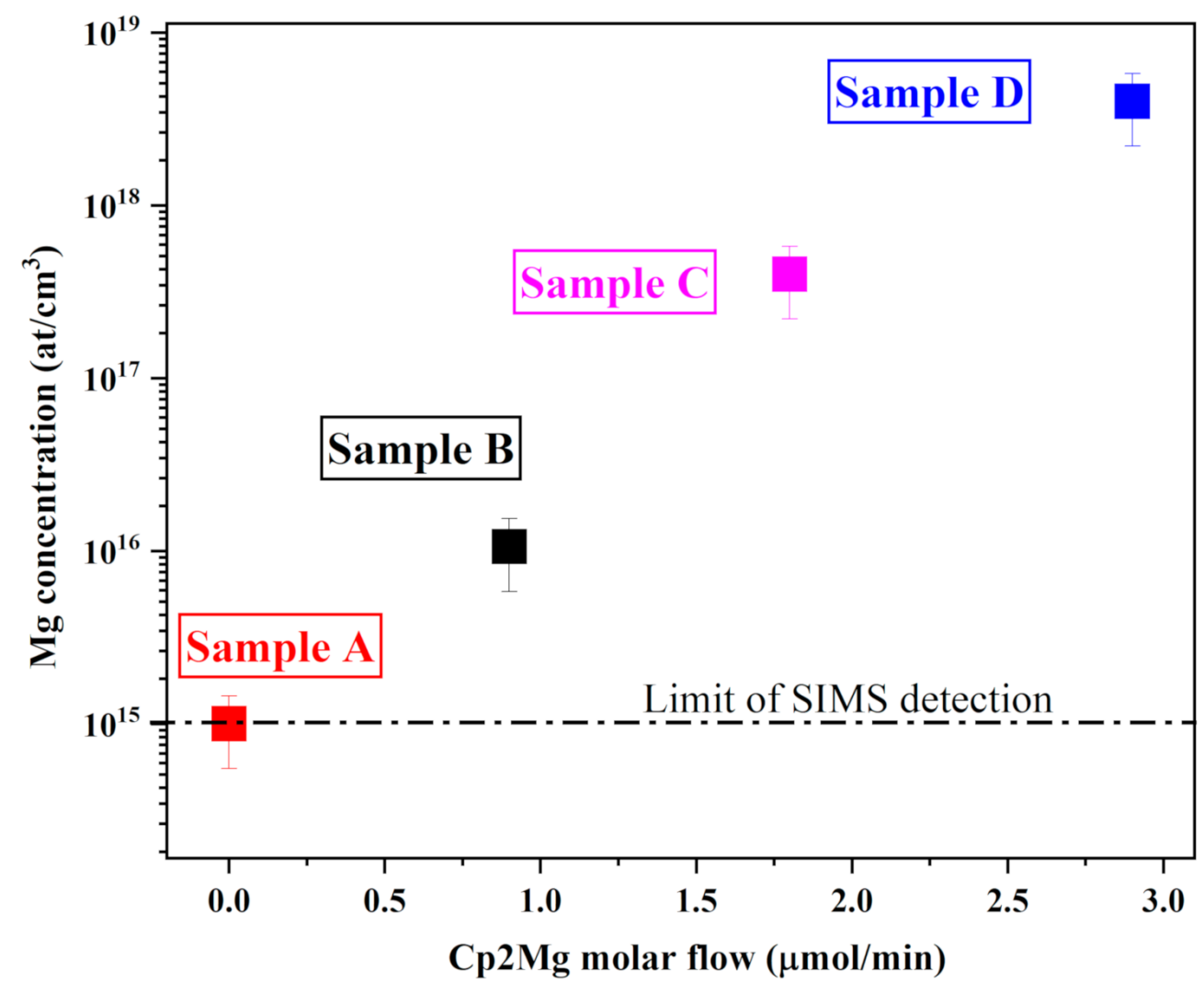

Figure 3. $\mathrm{Cp} 2 \mathrm{Mg}$ molar flow dependence of the $\mathrm{Mg}$ concentration.

\subsection{Ohmic Contact in h-BN Layers}

I-V measurements were performed on the four A-D samples. These measurements obtained information on lateral transport (perpendicular to the $c$-axis) in h-BN: the strong anisotropy of h-BN may result in different resistivity and transport in the vertical direction (parallel to the $c$-axis). Figure 4 shows the current measurement versus voltage recorded in the four h-BN samples. Whatever the sample, the I-V dependence was linear, confirming that the contacts are ohmic. It is also clear that increasing the $\mathrm{Mg}$ concentration results in an increase in the current for a given voltage. The dependence of the I-V slopes on the $\mathrm{Mg}$ concentration is reported in the inset of Figure 4. There was a large increase in the conductivity from sample A to sample B and then a slight increase from sample B to sample D. This behavior is probably related to the generation of point defects [31] with large $\mathrm{Mg}$ concentration in the layer, leading to a limitation (compensation) of the carrier diffusion length, especially for sample D. The resistivity of the undoped and the highly doped samples was determined from Van der Pauw (VdP) measurements performed at different temperatures (see Supplementary Materials). The resistivity was shown to vary between $1.5 \times 10^{6} \Omega \cdot \mathrm{cm}$ at $78 \mathrm{~K}$ and $2 \times 10^{3} \Omega \cdot \mathrm{cm}$ at $430 \mathrm{~K}$ for highly doped h-BN, and between $2 \times 10^{6} \Omega \cdot \mathrm{cm}$ at $78 \mathrm{~K}$ and $1 \times 10^{5} \Omega \cdot \mathrm{cm}$ at $430 \mathrm{~K}$ for undoped h-BN. At room temperature, the resistivity of the undoped sample (A) was $2 \times 10^{5} \Omega \cdot \mathrm{cm}$. Compared to literature reported results, this value is much smaller. Indeed, values of $7.1 \times 10^{14} \Omega \cdot \mathrm{cm}$ have been reported for $50 \mu \mathrm{m}$ thick undoped BN layer [32] and between $4 \times 10^{13}$ and $2.1 \times 10^{15} \Omega \cdot \mathrm{cm}$ for h-BN ceramics obtained by a field assisted sintering technique of h-BN powders [33]. This large difference can be attributed to the degree of disorder in sintering, the difference in layer thickness but also to some residual impurities such as carbon and oxygen, as revealed by SIMS measurements (not shown here).

At room temperature, the resistivity of the sample with the highest doping (D) was $2 \times 10^{4} \Omega \cdot \mathrm{cm}$, with a doping concentration of $5 \times 10^{15} \mathrm{~cm}^{-3}$. These values can be compared to those obtained by Sun et al. [20] who reported a resistivity and doping concentration of $1.2 \times 10^{-5} \Omega \cdot \mathrm{cm}$ and of $1.7 \times 10^{14} \mathrm{~cm}^{-2}$, respectively, for an h-BN monolayer grown on $\mathrm{Cu}$ 
foil and transferred on $\mathrm{SiO}_{2}$. For a thicker layer of h-BN (300 nm), the reported resistivity and doping concentration are $2.3 \Omega \cdot \mathrm{cm}$ and $1.1 \times 10^{18} \mathrm{~cm}^{-3}[7,8]$, respectively.

For the doped layer, an activation energy of $160 \mathrm{meV}$ was derived from the slope of the Arrhenius plot (see Supplementary Materials) and attributed to the Mg level in h-BN, which is in the range of the reported values $(30-300 \mathrm{meV}$ ) in the literature for $\mathrm{Mg}$ doped BN films $[18,19]$.

The $p$-type conductivity was confirmed by the positive Hall voltage $V_{H}$ derived from Hall measurement. Using this $\mathrm{V}_{\mathrm{H}}$ value and the sheet resistance deduced from the VdP measurements, we determined in the highly doped sample D a p-type carrier concentration of $5 \times 10^{15} \mathrm{~cm}^{-3}$, which is two orders of magnitude lower than the Mg atomic concentration measured by SIMS. One can then estimate the electrical activation of $\mathrm{Mg}$ around $1 \%$.

In order to further investigate the p-type conductivity, we designed and studied a p-n $\mathrm{h}-\mathrm{BN} / \mathrm{n}-\mathrm{AlGaN}$ heterojunction as discussed below.

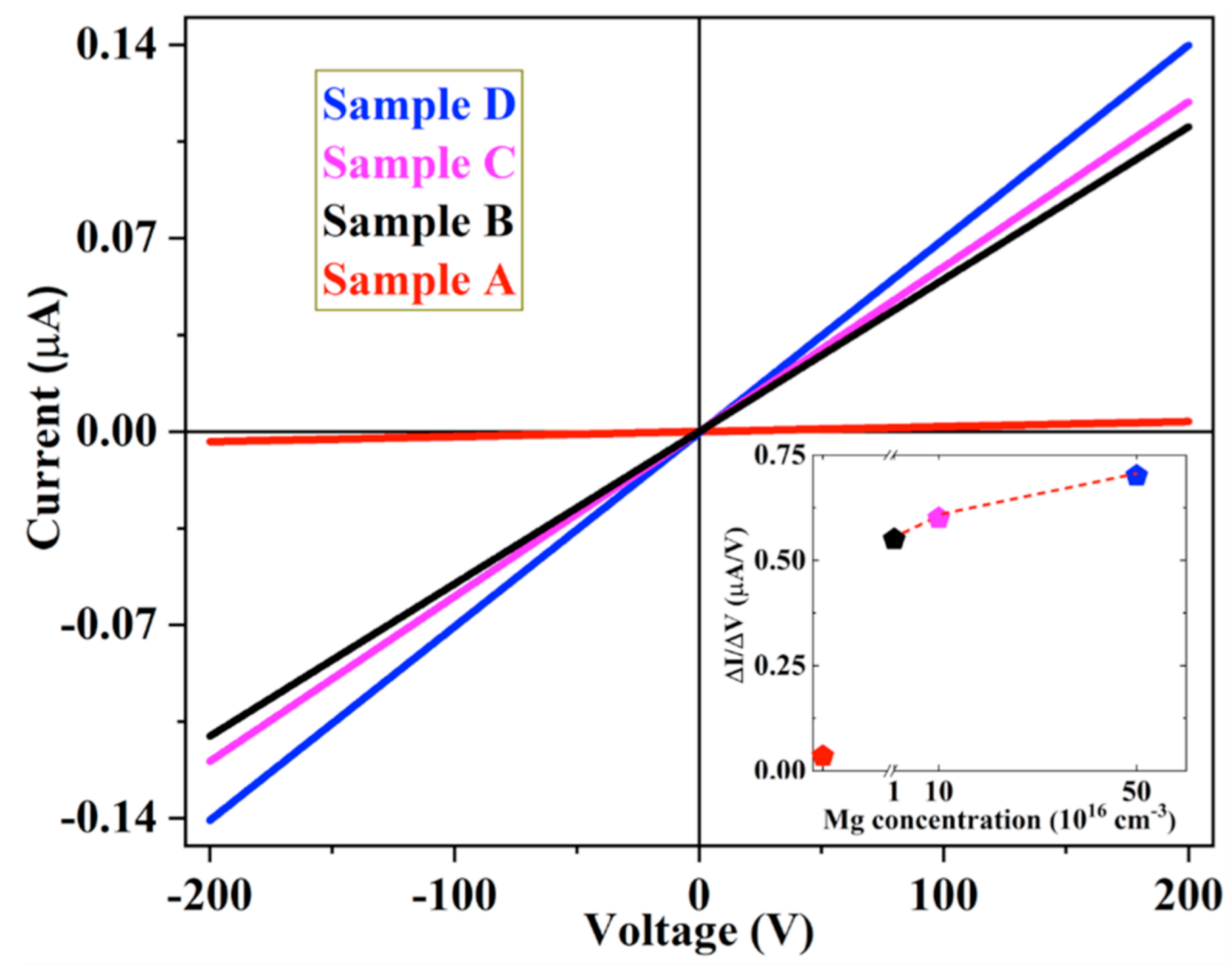

Figure 4. Current versus voltage measurements recorded in the undoped and Mg-doped h-BN A-D samples. The inset shows the variation of the slope of the different curves with the Mg concentration.

\section{4. $M g$ Doped $h-B N / n-A l G a N$ Heterostructures}

$\mathrm{H}-\mathrm{BN} / \mathrm{AlGaN}$ heterostructures were realized by growing undoped and $\mathrm{Mg}$ doped h-BN layer on Si doped $\mathrm{Al}_{0.58} \mathrm{Ga}_{0.42} \mathrm{~N} / \mathrm{AlN}$ / sapphire template wafer denoted by samples $\mathrm{E}$ and F, respectively. Figure 5 shows the measured HR-XRD 20- $\omega$ symmetric scan of (002) peak of the grown heterostructures. Clear diffraction peaks were identified at $25.8^{\circ}$, $35.3^{\circ}$ and $36.1^{\circ}$ which correspond to (002) reflection of h-BN, AlGaN (58\% Al) and $\mathrm{AlN}$, respectively. No other diffraction peak related to $\mathrm{BN}$ was observed by HRXRD scans indicating that the h-BN layer on AlGaN/AlN template is single phase. 


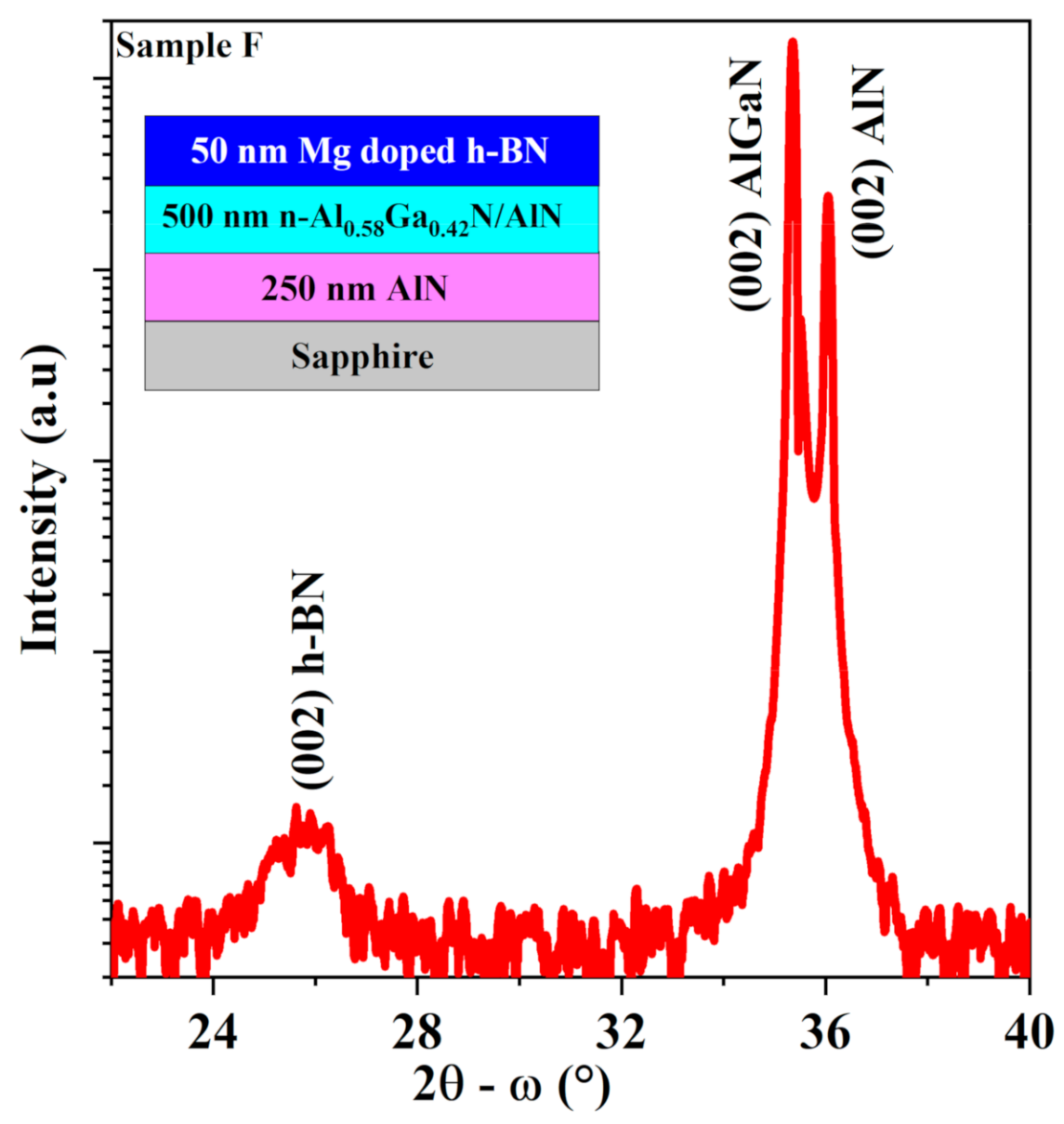

Figure 5. HR-XRD 2 $\theta-\omega$ symmetric scans of the $\mathrm{Mg}$ doped h-BN/n- $\mathrm{Al}_{0.58} \mathrm{Ga}_{0.42} \mathrm{~N} / \mathrm{AlN} /$ sapphire heterostructures (Sample F). Inset shows the grown structure.

Typical I-V curves of the undoped and $\mathrm{Mg}$ doped h-BN on n-AlGaN heterostructures recorded at room temperature are illustrated in Figure 6. Remarkably, at forward bias, the current of $\mathrm{Mg}$ doped $\mathrm{h}-\mathrm{BN} / \mathrm{n}$-AlGaN device was 7 orders of magnitude higher than that of the undoped $\mathrm{h}-\mathrm{BN} / \mathrm{n}-\mathrm{AlGaN}$ one. In the $\mathrm{Mg}$ doped $\mathrm{h}-\mathrm{BN} / \mathrm{n}-\mathrm{AlGaN}$ device (sample F), the leakage current under reverse bias voltage was reasonably low with a value of $1 \mu \mathrm{A}$ at $-10 \mathrm{~V}$, but it was not saturated as expected for an ideal p-n diode, and it continued to increase with the reverse voltage. This suggests that there are leakage current paths related to the deep defect levels in the depletion layer of h-BN [34].

The reverse and forward I-V characteristics of the $\mathrm{p}-\mathrm{hBN} / \mathrm{n}-\mathrm{AlGaN}$ heterojunctions were studied at different temperature from 123 to $423 \mathrm{~K}$ as shown in the semilogarithmic plot of Figure 7. At forward bias, all the I-V curves exhibited strong saturation due to high series resistance, which likely originated from the resistance of the long lateral path in $\mathrm{n}-\mathrm{AlGaN}$, which had a measured carrier concentration of $1.03 \times 10^{17} \mathrm{~cm}^{-3}$. As seen in the inset of Figure 8, the $2 \times 2 \mathrm{~mm}^{2}$ ohmic contact pads were $3 \mathrm{~mm}$ away from each other, which is much larger than the 50 and $500 \mathrm{~nm}$ thickness of the h-BN and n-AlGaN layers, respectively, so that the resistance of the n-AlGaN layer in the lateral direction was much larger than the resistance of the heterojunction in the vertical one. As shown in Figure 7, the current increased significantly with the temperature in the range 300 to $373 \mathrm{~K}$ and then started to saturate at higher temperature. An inverse trend was observed for the threshold voltage. It varied from $3.2 \mathrm{~V}$ at $123 \mathrm{~K}$ to $1.5 \mathrm{~V}$ at $423 \mathrm{~K}$. This might be due to the activation of some defects with the temperature increase. This assumption is consistent with the increase in the current at reverse bias with the temperature. For instance, at $-5 \mathrm{~V}$, the leakage current increased from $30 \mathrm{pA}$ at $123 \mathrm{~K}$ to $0.2 \mathrm{~mA}$ at $423 \mathrm{~K}$. 


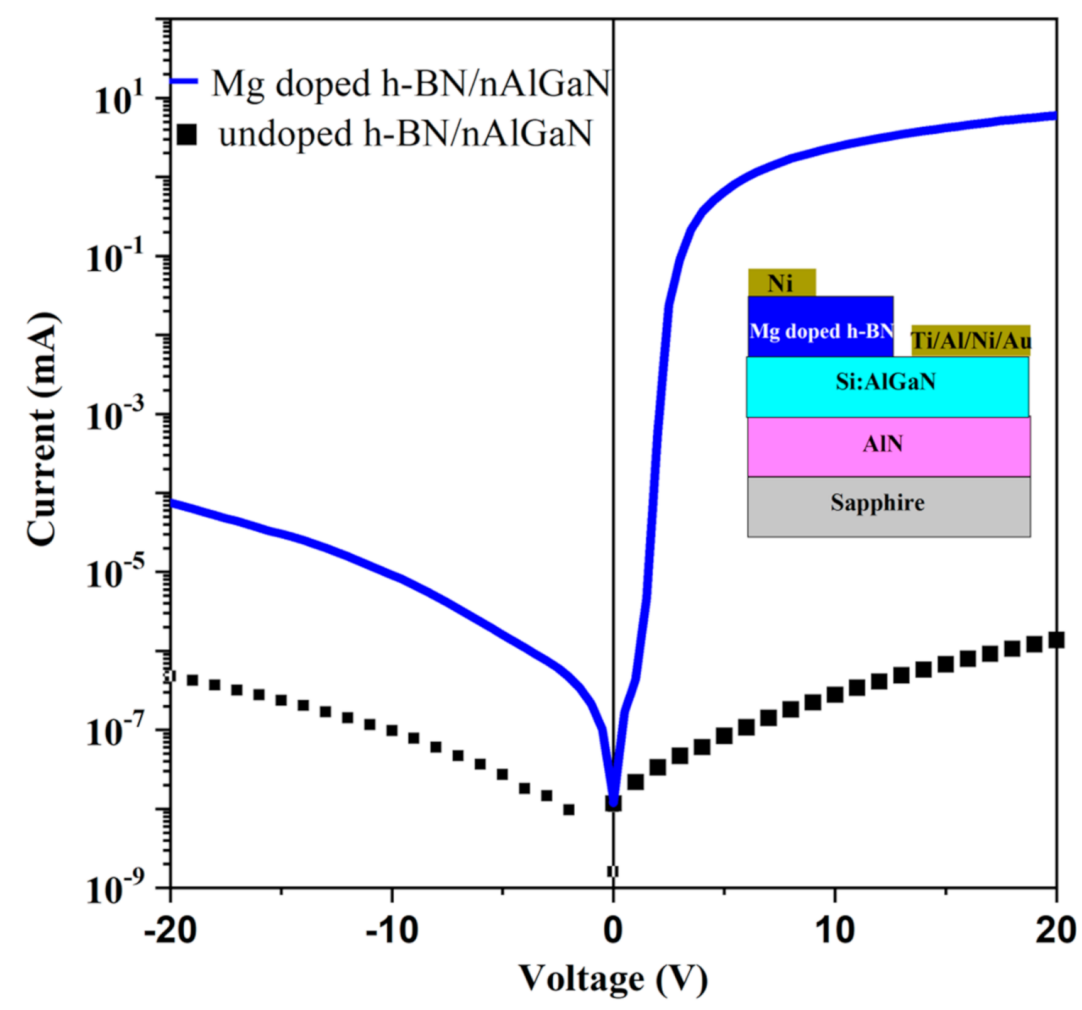

Figure 6. Current-voltage characteristics of undoped and $\mathrm{Mg}$ doped $\mathrm{BN} / \mathrm{n}-\mathrm{Al}_{0.58} \mathrm{Ga}_{0.42} \mathrm{~N}$ (Samples $\mathrm{E}$ and $\mathrm{F}$ ) devices measured at room temperature.

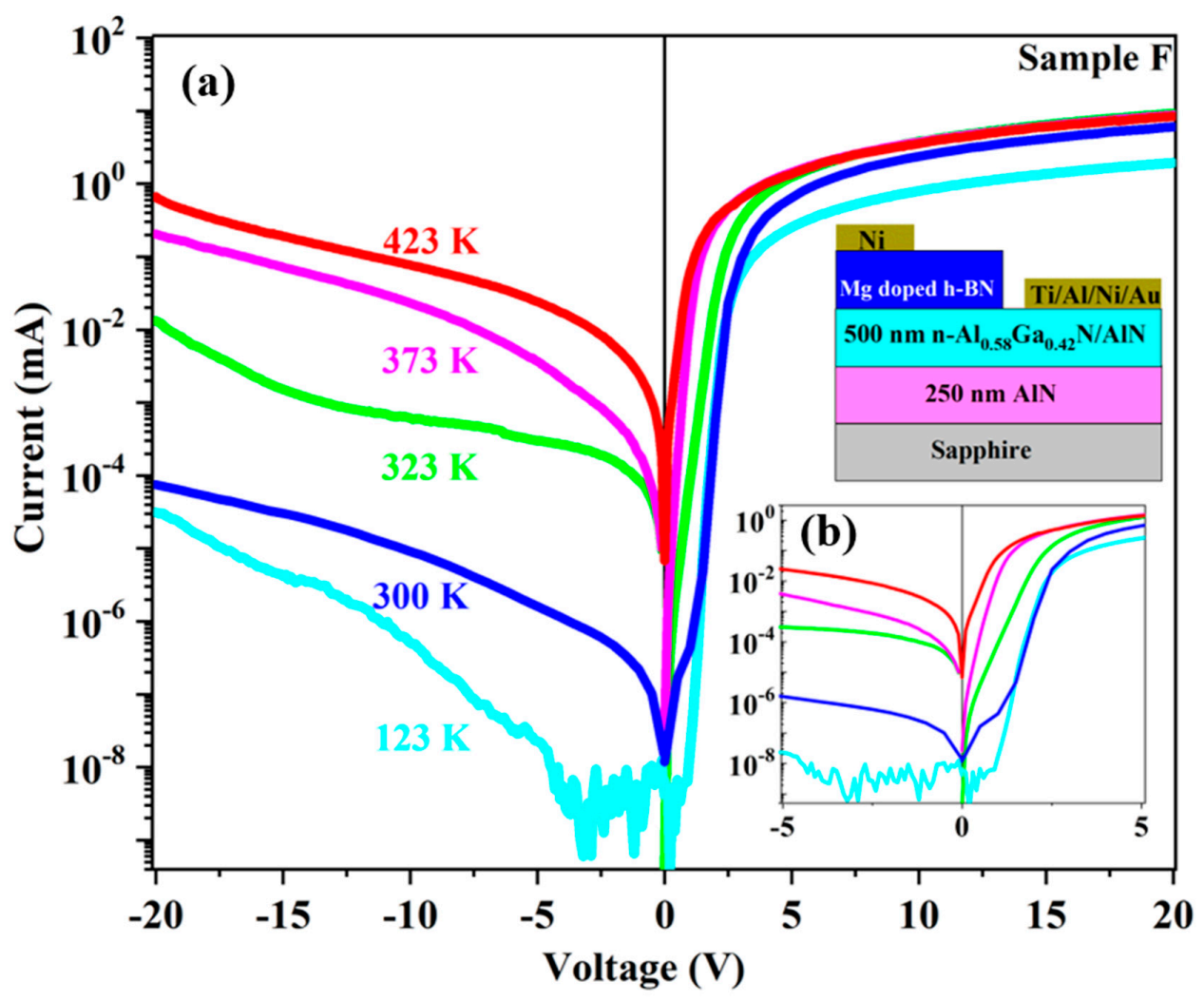

Figure 7. (a) $\mathrm{I}-\mathrm{V}$ characteristics of $\mathrm{Mg}$ doped $\mathrm{BN} / \mathrm{n}-\mathrm{Al}_{0.58} \mathrm{Ga}_{0.42} \mathrm{~N}$ (Sample $\mathrm{F}$ ) device recorded at different temperatures. Inset (b): I-V zoom-in of sample F. 


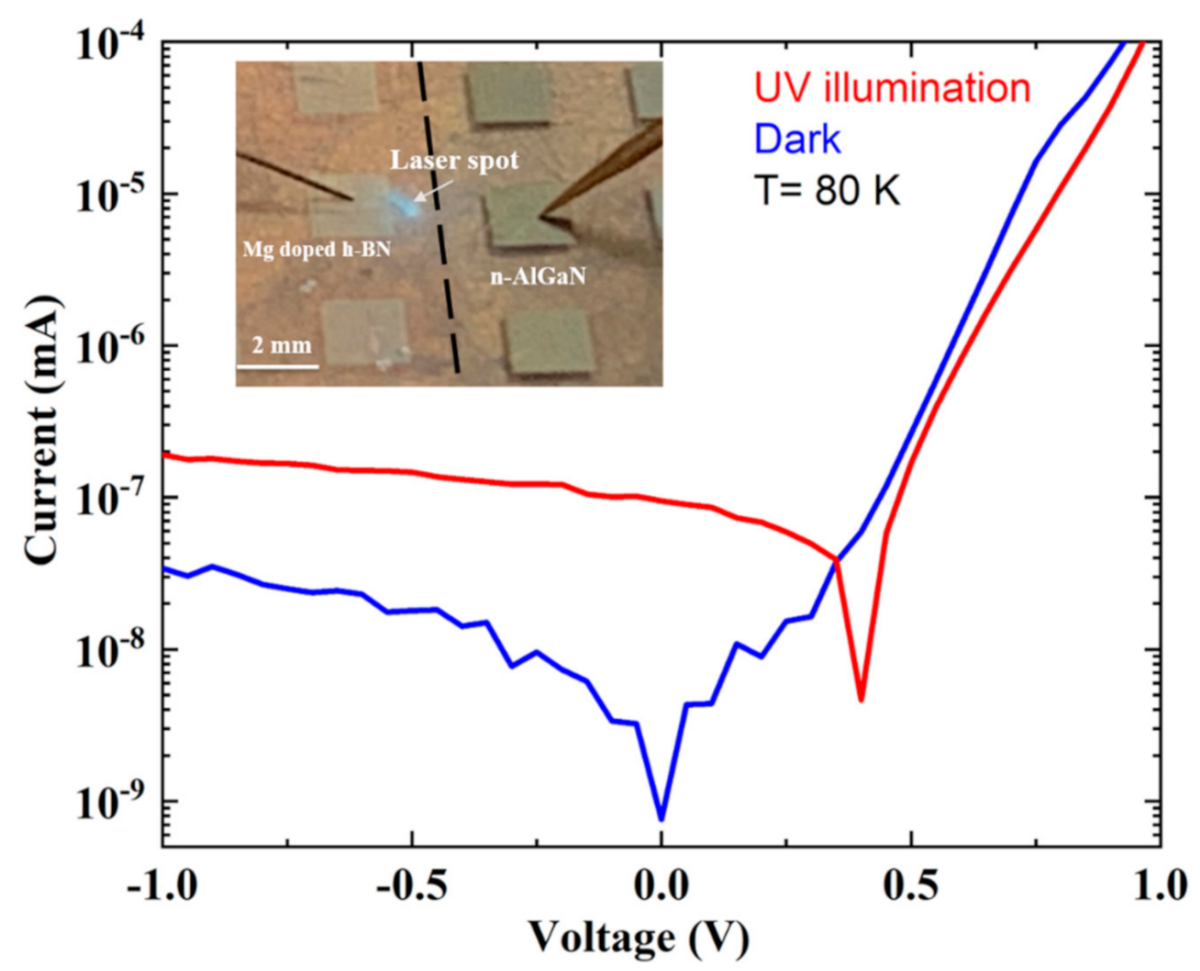

Figure 8. $\mathrm{I}-\mathrm{V}$ curve recorded in $\mathrm{Mg}$ doped $\mathrm{h}-\mathrm{BN} / \mathrm{n}-\mathrm{Al}_{0.58} \mathrm{Ga}_{0.42} \mathrm{~N}$ (Sample $\mathrm{F}$ ) at $\mathrm{T}=80 \mathrm{~K}$ with and without UV laser illumination. The inset shows a photograph of the top view of the heterojunction with the electrical contact pad and the location of the laser spot.

As the heterojunction showed better I-V characteristics at low temperature (low current leak), a set of P-N diodes were cooled to liquid nitrogen temperature and illuminated under UV laser light at $266 \mathrm{~nm}$. Illumination occurred on the $\mathrm{p}$-side of the junction through the $\mathrm{Mg}$ doped h-BN, next to the contact pad, as shown in the inset of Figure 8. As the $266 \mathrm{~nm}$ laser was below the bandgap of $\mathrm{h}-\mathrm{BN}$ and above the bandgap of $\mathrm{Al}_{0.58} \mathrm{Ga}_{0.42} \mathrm{~N}$, UV absorption primarily occurred in the $\mathrm{Al}_{0.58} \mathrm{Ga}_{0.42} \mathrm{~N}$. Even with low output power laser of $10 \mathrm{~mW}$, the partial absorption of the glass window of the cryostat, and the likely low collection efficiency hindered by the lateral transport in both h-BN and $\mathrm{AlGaN}$, a significant photocurrent (120 pA at 0 bias voltage) was obtained. The generation of a photocurrent is evidence of the existence of built-in electrical field at the junction between $\mathrm{Mg}$ doped h-BN and $\mathrm{n}-\mathrm{AlGaN}$.

$\mathrm{CV}$ measurements at room temperature and $1 / \mathrm{C}^{2}$ plot versus voltage are both shown in Figure 9. For forward voltage, the capacitance measurement was limited to small voltages since the forward bias current and the diffusion capacitance affect the accuracy of the capacitance measurement. For reverse applied voltage, the capacitance decreased, as expected for a p-n diode, since the depletion region width increased accordingly. At larger negative voltage, the capacitance did not saturate, which indicates a moderate $\mathrm{p}$-doping concentration (here, we assume that the n-doping concentration of the AlGaN layer is much larger than the $\mathrm{p}$-doping concentration of the $\mathrm{h}$ - $\mathrm{BN}$ layer, leading to a depletion mostly located in the h-BN layer). The dotted line in the $1 / \mathrm{C}^{2}$ plot formed a reasonable linear fit at voltage close to zero from which one can conclude that the doping concentration was almost constant close to the $\mathrm{Mg}$ doped $\mathrm{hBN} / \mathrm{n}-\mathrm{AlGaN}$ interface. Extrapolation of the low voltage $1 / C^{2}$ measurements (see Figure 9 ) resulted in a built-in voltage of $3.9 \mathrm{~V}$, consistent with the bandgap of the $\mathrm{Al}_{0.58} \mathrm{Ga}_{0.42} \mathrm{~N}$ material, and a small discontinuity between the valence bands of h-BN and $\mathrm{AlGaN}$ as reported in XPS heterostructure experiments [35]. It is worth mentioning that the measured capacitance was much lower than that expected for a $2 \times 2 \mathrm{~mm}^{2}$ surface area of the device. This could be attributed to either a partial oxidation of the Ni pad (the current spread in the pad has been noticed to decrease with 
time) leading to a decrease in the effective surface area and/or a large resistance of the $\mathrm{AlGaN}$ path, which attenuates the AC capacitance signal. This makes extraction of the $\mathrm{p}$ doping from the $\mathrm{C}-\mathrm{V}$ measurements complicated.

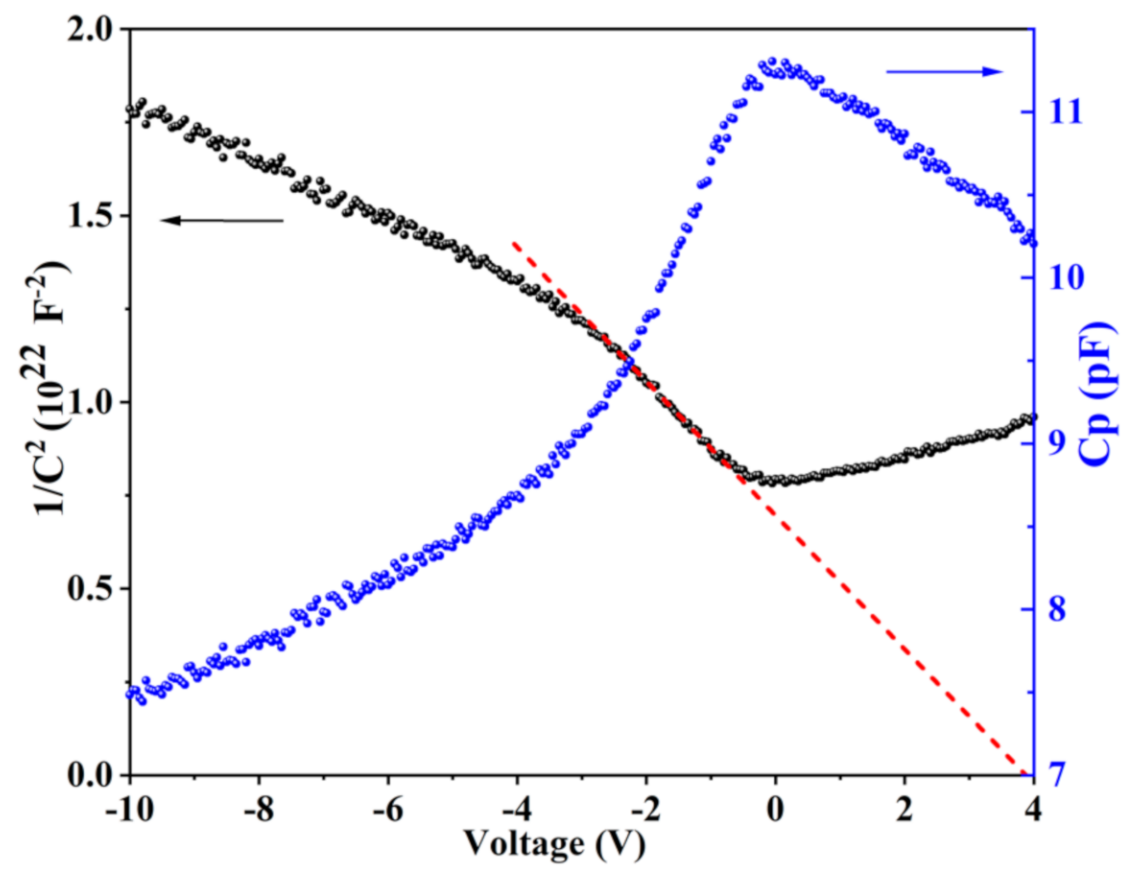

Figure 9. Capacitance voltage measurement in $\mathrm{Mg}$ doped h-BN/n- $\mathrm{Al}_{0.58} \mathrm{Ga}_{0.42} \mathrm{~N}$ (Sample F) measured at $1 \mathrm{MHz}$ and room temperature, and corresponding $1 / \mathrm{C}^{2}$ plot versus voltage.

\section{Conclusions}

In summary, we used MOVPE to grow h-BN layers with different $\mathrm{Cp} 2 \mathrm{Mg}$ molar flow rates. The van der Waals nature of the Mg-doped h-BN layers was retained up to a certain threshold value of the $\mathrm{Cp} 2 \mathrm{Mg}$ molar flow. The electrical conductivity of $\mathrm{Mg}$ doped h-BN layers increased with $\mathrm{Mg}$ concentration, showing the possibility to control conductivity of h-BN. We demonstrated epitaxial growth of Mg-doped h-BN layers on Al rich $\mathrm{n}-\mathrm{AlGaN}$ layers, which exhibited diode-like I-V characteristics. More importantly, the illumination of $\mathrm{p}-\mathrm{BN} / \mathrm{n}-\mathrm{AlGaN}$ heterojunction generated significant photocurrent, which is very convincing evidence of the $\mathrm{p}-\mathrm{n}$ junction formation between $\mathrm{p}-\mathrm{BN}$ and $\mathrm{n}-\mathrm{AlGaN}$. $\mathrm{C}-\mathrm{V}$ measurements were also consistent with a built-in voltage around $4.0 \mathrm{~V}$. These results are very encouraging for further research and may open potential applications in wide bandgap optoelectronic devices such as deep UV LEDs, deep UV lasers and novel neutron detector structures.

Supplementary Materials: See Supplementary Materials for the resistivity measurement of sample $\mathrm{D}$ and I-V characteristics of Samples $\mathrm{F}$ in the attached file. The following are available online at https: / www.mdpi.com/2079-4991/11/1/211/s1, Figure S1: Resistivity of the $50 \mathrm{~nm}$ thick undoped and Mg-doped h-BN (sample D) versus temperature. Figure S2: Activation energy of the $50 \mathrm{~nm}$ thick $\mathrm{Mg}$-doped h-BN. Figure S3: I-V characteristics measured on two Mg doped BN contact pads and two n-AlGaN contact pads.

Author Contributions: A.O. contributed to the design of the study and supervised the whole project. A.M. performed SEM and XRD, analyzed the results and wrote the manuscript. A.M., S.S. and P.V. performed the epitaxial growth. A.M., S.K., Y.H., S.G., A.A., A.S., P.L.V. and J.P.S. were responsible for the processing of $\mathrm{Mg}$-doped $\mathrm{h}-\mathrm{BN} / \mathrm{n}-\mathrm{AlGaN}$ heterostructures and the electrical characterization. All authors contributed to discussion of the results. All authors reviewed and commented on the manuscript. All authors have read and agreed to the published version of the manuscript. 
Funding: This study was partially funded by the French National Research Agency (ANR) under the GANEX Laboratory of Excellence (Labex) project and French PIA project Lorraine Universite d'Excellence (Grant ANR-15-IDEX-04-LUE), as well as the Grand Est Region in France.Informed Consent: Not applicable.

Data Availability Statement: The data that support the findings of this study are available within the article or from the corresponding author upon reasonable request.

Conflicts of Interest: The authors declare no conflict of interest.

\section{References}

1. Li, J.; Oder, T.N.; Nakarmi, M.L.; Lin, J.Y.; Jiang, H.X. Optical and electrical properties of Mg-doped p-type AlxGa 1-xN. Appl. Phys. Lett. 2002, 80, 1210-1212. [CrossRef]

2. Nakarmi, M.L.; Kim, K.H.; Khizar, M.; Fan, Z.Y.; Lin, J.Y.; Jiang, H.X. Electrical and optical properties of Mg-dopedAl 0.7Ga 0.3N alloys. Appl. Phys. Lett. 2005, 86, 1-3. [CrossRef]

3. Nakarmi, M.L.; Nepal, N.; Ugolini, C.; Altahtamouni, T.M.; Lin, J.Y.; Jiang, H.X. Correlation between optical and electrical properties of Mg-doped AlN epilayers. Appl. Phys. Lett. 2006, 89, 152120-152123. [CrossRef]

4. Taniyasu, Y.; Kasu, M.; Makimoto, T. An aluminium nitride light-emitting diode with a wavelength of 210 nanometres. Nature 2006, 441, 325-328. [CrossRef]

5. Pernot, C.; Kim, M.; Fukahori, S.; Inazu, T.; Fujita, T.; Nagasawa, Y.; Hirano AIppommatsu, M.; Iwaya, M.; Kamiyama, S.; Akasaki, I.; et al. Improved efficiency of 255-280 nm AlGaN-based light-emitting diodes. Appl. Phys. Express 2010, 3, 061003061004. [CrossRef]

6. Watanabe, K.; Taniguchi, T.; Niiyama, T.; Miya, K.; Taniguchi, M. Far-ultraviolet plane-emission handheld device based on hexagonal boron nitride. Nat. Photonics 2009, 3, 591-594. [CrossRef]

7. Dahal, R.; Li, J.; Majety, S.; Pantha, B.N.; Cao, X.K.; Lin, J.Y.; Jiang, H.X. Epitaxially grown semiconducting hexagonal boron nitride as a deep ultraviolet photonic material. Appl. Phys. Lett. 2011, 98, 88-91. [CrossRef]

8. Majety, S.; Li, J.; Cao, X.K.; Dahal, R.; Pantha, B.N.; Lin, J.Y.; Jiang, H.X. Epitaxial growth and demonstration of hexagonal BN/AlGaN p-n junctions for deep ultraviolet photonics. Appl. Phys. Lett. 2012, 100. [CrossRef]

9. Huang, B.; Cao, X.K.; Jiang, H.X.; Lin, J.Y.; Wei, S.H. Origin of the significantly enhanced optical transitions in layered boron nitride. Phys. Rev. B Condens. Matter Mater. Phys. 2012, 86, 1-5. [CrossRef]

10. Jiang, H.X.; Lin, J.Y. Review-Hexagonal Boron Nitride Epilayers: Growth, Optical Properties and Device Applications ECS. J. Solid State Sci. Technol. 2017, 6, Q3012-Q3021. [CrossRef]

11. Maity, A.; Grenadier, S.J.; Li, J.; Lin, J.Y.; Jiang, H.X. High sensitivity hexagonal boron nitride lateral neutron detectors. Appl. Phys. Lett. 2019, 114, 222102-222104. [CrossRef]

12. Li, X.; Jordan, M.B.; Ayari, T.; Sundaram, S.; El Gmili, Y.; Alam, S.; Alam, M.; Patriarche, G.; Voss, P.L.; Salvestrini, J.P.; et al. Flexible metal-semiconductor-metal device prototype on wafer-scale thick boron nitride layers grown by MOVPE. Sci. Rep. 2017, 7, 1-8. [CrossRef] [PubMed]

13. Nose, K.; Oba, H.; Yoshida, T. Electric conductivity of boron nitride thin films enhanced by in situ doping of zinc. Appl. Phys. Lett. 2006, 89, 3-6. [CrossRef]

14. Attaccalite, C.; Bockstedte, M.; Marini, A.; Rubio, A.; Wirtz, L. Coupling of excitons and defect states in boron-nitride nanostructures. Phys. Rev. B Condens. Matter Mater. Phys. 2011, 83, 1-8. [CrossRef]

15. Laleyan, D.A.; Zhao, S.; Woo, S.Y.; Tran, H.N.; Le, H.B.; Szkopek, T.; Guo, H.; Botton, G.A.; Mi, Z. AlN/h-BN Heterostructures for Mg Dopant-Free Deep Ultraviolet Photonics. Nano Lett. 2017, 17, 3738-3743. [CrossRef]

16. Watanabe, M.O.; Itoh, S.; Mizushima, K.; Sasaki, T. Electrical properties of BC2N thin films prepared by chemical vapor deposition. J. Appl. Phys. 1995, 78, 2880-2882. [CrossRef]

17. Uddin, M.R.; Li, J.; Lin, J.Y.; Jiang, H.X. Probing carbon impurities in hexagonal boron nitride epilayers. Appl. Phys. Lett. 2017, 110, 182107. [CrossRef]

18. Lu, M.; Bousetta, A.; Bensaoula AWaters, K.; Schultz, J.A. Electrical properties of boron nitride thin films grown by neutralized nitrogen ion assisted vapor deposition. Appl. Phys. Lett. 1995, 5, 622-624. [CrossRef]

19. He, B.; Zhang, W.J.; Yao, Z.Q.; Chong, Y.M.; Yang, Y.; Ye, Q.; Pan, X.J.; Zapien, J.A.; Bello, I.; Lee, S.T.; et al. P -type conduction in beryllium-implanted hexagonal boron nitride films. Appl. Phys. Lett. 2009, 95, 252106. [CrossRef]

20. Sun, F.; Hao, Z.; Liu, G.; Wu, C.; Lu, S.; Huang, S.; Liu, C.; Hong, Q.; Chen, X.; Cai, D.; et al. P-Type conductivity of hexagonal boron nitride as a dielectrically tunable monolayer: Modulation doping with magnesium. Nanoscale 2018, 10, 4361-4369. [CrossRef] [PubMed]

21. Weston, L.; Wickramaratne, D.; Van De Walle, C.G. Hole polarons and p-type doping in boron nitride polymorphs. Phys. Rev. B 2017, 96, 1-4. [CrossRef]

22. Li, X.; Sundaram, S.; El Gmili, Y.; Ayari, T.; Puybaret, R.; Patriarche, G.; Voss, P.L.; Salvestrini, J.P.; Ougazzaden, A. Large-area two-dimensional layered hexagonal boron nitride grown on sapphire by metalorganic vapor phase epitaxy. Cryst. Growth Des. 2016, 16, 3409-3415. [CrossRef] 
23. Ayari, T.; Sundaram, S.; Li, X.; El Gmili, Y.; Voss, P.L.; Salvestrini, J.P.; Ougazzaden, A. Wafer-scale controlled exfoliation of metal organic vapor phase epitaxy grown InGaN/GaN multi quantum well structures using low-tack two-dimensional layered h-BN. Appl. Phys. Lett. 2016, 108, 171105-171106. [CrossRef]

24. Snure, M.; Paduano, Q.; Kiefer, A. Effect of surface nitridation on the epitaxial growth of few-layer sp2BN. J. Cryst. Growth 2016, 436, 16-22. [CrossRef]

25. Paduano, Q.; Snure, M.; Weyburne, D.; Kiefer, A.; Siegel, G.; Hu, J. Metalorganic chemical vapor deposition of few-layer sp2bonded boron nitride films. J. Cryst. Growth 2016, 449, 148-155. [CrossRef]

26. Yang, X.; Nitta, S.; Nagamatsu, K.; Bae, S.Y.; Lee, H.J.; Liu, Y.; Pristovsek, M.; Honda, Y.; Amano, H. Growth of hexagonal boron nitride on sapphire substrate by pulsed-mode metalorganic vapor phase epitaxy. J. Cryst. Growth 2018, 482, 1-8. [CrossRef]

27. Chugh, D.; Wong-Leung, J.; Li, L.; Lysevych, M.; Tan, H.H.; Jagadish, C. Flow modulation epitaxy of hexagonal boron nitride 2D. Materials 2018, 5, 045018-045022.

28. Bayram, C.; Pau, J.L.; McClintock, R.; Razeghi, M. Delta-doping optimization for high quality p -type GaN. J. Appl. Phys. 2008, 104, 1-6. [CrossRef]

29. Lachab, M.; Youn, D.H.; Qhalid Fareed, R.S.; Wang, T.; Sakai, S. Characterization of Mg-doped GaN grown by metalorganic chemical vapor deposition. Solid. State. Electron. 2000, 44, 1669-1677. [CrossRef]

30. Hsu, C.C.; Yuan, J.S.; Cohen, R.M.; Stringfellow, G.B. Doping studies for InP grown by organometallic vapor phase epitaxy. J. Cryst. Growth 1986, 74, 535-542. [CrossRef]

31. Henck, H.; Pierucci, D.; Ben Aziza, Z.; Silly, M.G.; Gil, B.; Sirotti, F.; Cassabois, G.; Ouerghi, A. Stacking fault and defects in single domain multilayered hexagonal boron nitride. Appl. Phys. Lett. 2017, 110, 023101-023105. [CrossRef]

32. Maity, A.; Grenadier, S.J.; Li, J.; Lin, J.Y.; Jiang, H.X. Hexagonal boron nitride neutron detectors with high detection efficiencies. J. Appl. Phys. 2018, 123, 1-8. [CrossRef]

33. Steinborn, C.; Herrmann, M.; Keitel, U.; Schönecker, A.; Räthel, J.; Rafaja, D.; Eichler, J. Correlation between microstructure and electrical resistivity of hexagonal boron nitride ceramics. J. Eur. Ceram. Soc. 2013, 33, 1225-1235. [CrossRef]

34. Narushima, S.; Mizoguchi, H.; Shimizu, K.I.; Ueda, K.; Ohta, H.; Hirano, M.; Kamiya, T.; Hosono, H. A p-type amorphous oxide semiconductor and room temperature fabrication of amorphous oxide $\mathrm{p}$-n heterojunction diodes. Adv. Mater. 2003, 15, 1409-1413. [CrossRef]

35. Hao, G.D.; Tsuzuki, S.; Inoue, S. Small valence band offset of h-BN/Al 0.7 Ga $0.3 \mathrm{~N}$ heterojunction measured by X-ray photoelectron spectroscopy. Appl. Phys. Lett. 2019, 114, 1-6. [CrossRef] 